\title{
High-Resolution Laser Ablation-Inductively Coupled Plasma-Mass Spectrometry Imaging of Cisplatin-Induced Nephrotoxic Side Effects
}

Thibaut Van Acker ${ }^{\mathrm{a}}$, Stijn J. M. Van Malderen ${ }^{\mathrm{a}}$, Marjolein Van Heerden ${ }^{\mathrm{b}}$, James Eric McDuffie ${ }^{\mathrm{c}}$, Filip Cuyckens ${ }^{\mathrm{b}}$ and Frank Vanhaecke ${ }^{\mathrm{a}}{ }^{*}$

${ }^{a}$ Department of Analytical Chemistry, Ghent University, Campus Sterre, Krijgslaan 281 - S12, 9000 Ghent, Belgium

${ }^{b}$ Preclinical Development and Safety, Janssen Research and Development, Turnhoutseweg 30, 2340 Beerse, Belgium

${ }^{c}$ Preclinical Development and Safety, Janssen Research and Development, 3210 Merryfield Row, San Diego, CA 92121, USA

${ }^{*}$ Corresponding author. E-mail address: Frank.Vanhaecke@UGent.be, fax number: +329 2644960 


\section{Abstract}

Two-dimensional elemental mapping (bioimaging) via laser ablation-inductively coupled plasma-mass spectrometry (LA-ICP-MS) was performed on $5 \mu \mathrm{m}$ thick formalin-fixed, paraffin-embedded kidney tissue sections from Cynomolgus monkeys administered with increasing pharmacological doses of cisplatin. Laterally resolved pixels of $1 \mu \mathrm{m}$ were achieved, enabling elemental analysis on a (sub-)cellular level. Zones of high Pt response were observed in the renal cortex, where proximal tubules are present, the epithelium of which is responsible for partial reabsorption of cisplatin. Histopathological evaluation, of hematoxylin and eosin-stained serial sections, adjacent to the sections probed via LA-ICP-MS, revealed minimal to mild cisplatin-related lesions $(<100 \mu \mathrm{m})$ in the renal cortex. Necrotic proximal tubules with sloughed epithelial cells in their lumen could be linked directly to the areas with the highest accumulation of cisplatin, indicating a direct link between cellular concentration and toxicity, thereby providing more insight into the mechanisms through which renal damage occurs.

\section{Keywords}

Cisplatin, mass spectrometry imaging, LA-ICP-MS, high-resolution, kidney

\section{Introduction}

Cisplatin (cis-diamminedichloroplatinum [II], CDDP) was the first platinum-containing chemotherapeutic agent and is now approved for the treatment of solid tumors, e.g., testicular, cervical, colorectal, lung, ovarian, head and neck cancer [1-3]. Unfortunately, a major drawback of cisplatin use is the occurrence of severe and dose-limiting side effects, e.g., vomiting, ototoxicity, neurotoxicity and nephrotoxicity [4]. Drug-induced kidney injury (DIKI) is an adverse event, in which excretion is disrupted due to exposure to toxic compounds [5]. No regulatory authority guidance regulates stand-alone kidney safety pharmacology studies. Therefore, exploratory repeat-dose DIKI studies are not routinely conducted by pharmaceutical companies, particularly not in non-human primates [6]. While the incidence of translatable DIKI is low, DIKI remains a significant cause of candidate drug attrition during the clinical drug development phase and post-marketing period [7]. Recently, DIKI has been reported to contribute to approximately $25 \%$ of the cases of hospital-acquired acute kidney injury (AKI) events [8]. Despite restricted patient doses [9], approximately one in three patients suffers from nephrotoxicity after cisplatin chemotherapy, which endangers the kidneys' vital functions in the genitourinary and cardiovascular systems $[3,4]$.

The renal system excretes metabolic waste products by filtering the blood and it is responsible for maintaining water, electrolyte and acid-base balances in the body. Moreover, the kidneys regulate the production of vitamin D, by synthesizing calcitriol, and the secretion of the hormone erythropoietin, which stimulates red blood cell production in the bone marrow [10]. Renal cortical and medullary tissue consists of vascular and tubular elements in close proximity to each other, with the interstitium, i.e. interstitial fluid and interstitial cells, in-between them [10]. In humans, a normal kidney consists of approximately 1 million of nephrons, which start in the cortex and end in the papilla [11]. Figure 1 provides a schematic representation of a short-looped and long-looped nephron. Each nephron is subdivided in multiple tubular segments, which differ functionally and structurally from one another, starting with the renal corpuscle, i.e. Bowman's capsule surrounding the glomerulus, a tuft of capillary loops through which the blood flows [11]. In this structure, blood filtration occurs 
whereby water, electrolytes and small proteins are removed from the capillaries and enter the Bowman's capsule [11]. This filtrate flows further into the proximal convoluted tubule (PCT) and proximal straight tubule, where large amounts of water, electrolytes, glucose and amino acids are reabsorbed from the filtrate [10]. Furthermore, secretion of some administered drugs takes place in this region of the nephron [10]. The next tubular segments are the loop of Henle, distal convoluted tubule (DCT), connecting tubule, cortical and medullary collecting ducts, which are all responsible for numerous reabsorption processes and the delivery of the final urine to the minor calyx $[10]$.

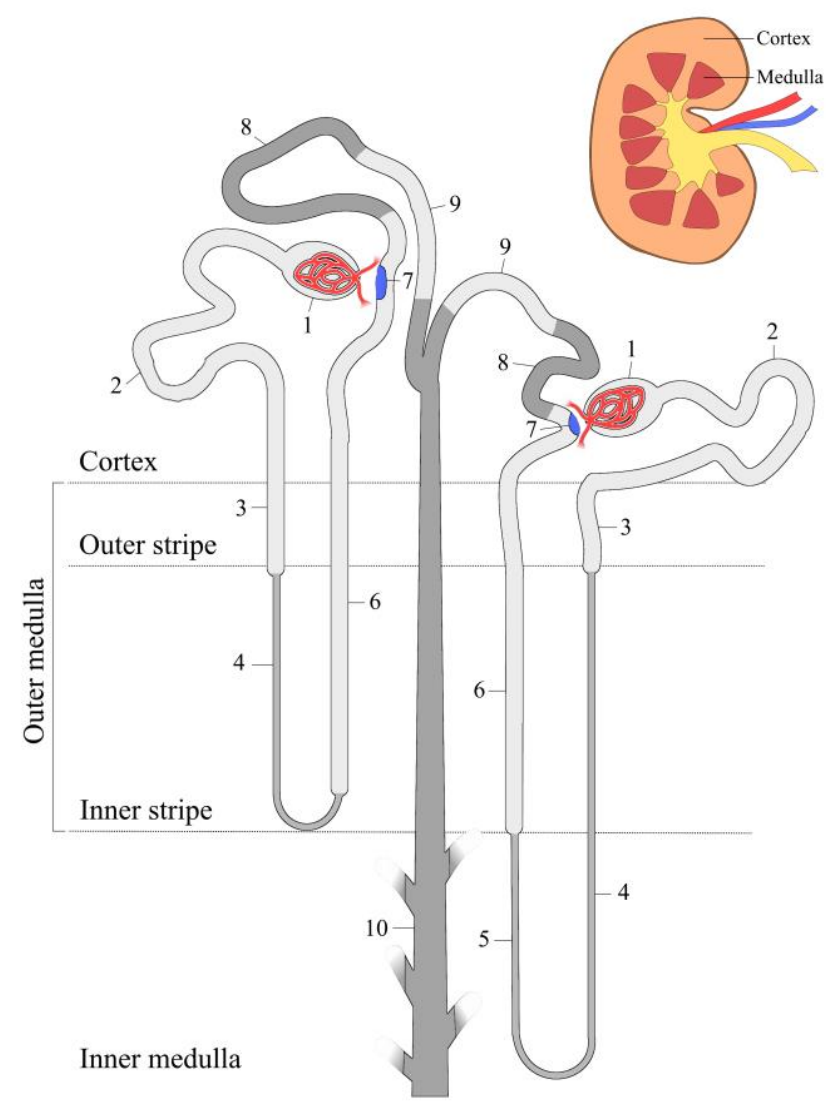

Figure 1. Schematic representation of the nephrons, the functional units of the kidney. The regions of the cortex, outer and inner stripe of the outer medulla and the inner medulla are separated by the dashed lines. The numbers are indicating different tubular segments: (1) renal corpuscle, (2) proximal convoluted tubule, (3) proximal straight tubule, (4) thin descending limb, (5) thin ascending limb, (6) thick ascending limb, (7) macula densa, (8) distal convoluted tubule, (9) connecting tubule and (10) collecting duct. The nomenclature is based on standard nomenclature for structures of the kidney [12].

In the case of nephrotoxicity, cisplatin accumulation can occur locally in renal tissue [13], where cisplatin is taken up in cortical tubular epithelial cells of proximal and distal tubules via passive diffusion and via copper transporters, P-type copper-transporting ATPases, multi-drug extrusion transporters and organic cation transporters (OCTs) [3,4,14,15]. In renal tissue, especially OCT2 plays a major role in cisplatin nephrotoxicity as being a kidney-specific transporter protein, it is omnipresent in proximal tubular epithelium at the basolateral membrane [3]. The identification of the molecular mechanisms involved is ongoing. Once cisplatin enters cells, it binds to nucleophilic molecules, e.g., proteins, RNA and DNA, which may trigger DNA cross-linking, apoptosis and necrosis [1,4]. Subsequently, this phenomenon may lead to severe renal tissue damage, decreased glomerular filtration rate and ultimately, renal failure [4]. Because 
the mechanisms responsible for nephron segment-specific DIKI remain poorly understood, there is a great need for sensitive, label-free methods for visualizing and quantifying the distribution of candidate drugs in the kidney to support investigational studies of nephrotoxicity during drug research and development.

Laser ablation-inductively coupled plasma-mass spectrometry (LA-ICP-MS) is a well-known analytical technique capable of performing quantitative spatially resolved analysis of elemental distributions with $\mu \mathrm{m}$ lateral resolution. The main features of LA-ICP-MS include minimal sample preparation, wide linear dynamic range, multi-element capability and low limits of detection. Bioimaging via LA-ICPMS was first proposed by Wang et al. [16] and has gradually gained interest in the bioanalytical field and has been utilized to visualize the distribution of endogenous metals in numerous tissues, e.g., mouse brain, heart and spinal cord tissue [17-20], human brain, lung, lymph node tissue and kidney stones [21-24] and metal-labelled antibodies designed to target specific antigens [25-31]. Analysis of the distribution of administered pharmaceutical agents such as cisplatin in target and non-target tissues has been performed in many studies [32-42], providing profound insights into depth of tissue penetration, metabolic fate in vivo, and serious adverse effects which, in turn, can enhance the success rate of utilizing cisplatin as a prototype to develop LA-ICP-MS methods that may be adapted to further evaluate candidate drugs or their metabolites with known kidney safety liabilities, particularly during the early stages of the drug development process [32].

Accurate quantification protocols in LA-ICP-MS require matrix-matched standards, online solution addition calibration, or isotope dilution [43-45]. A recent review by Limbeck et al. [46] summarized calibration strategies and approaches for the preparation of standards, including sections of spiked tissue homogenates [21], spiked blood [47], spiked polymethylmethacrylate spin-coated on quartz slides [48], printed standards [49-52], and dried droplet standards [53]. Based on their density and water content, spiked gelatin standards are pseudo-matrix-matched to biological tissues and can be applied as an inexpensive and simple alternative [34,54-56]. In this work, spiked gelatin droplet standards, with In as an internal standard, were prepared for quantification purposes. A low dispersion mixing bulb, ARIS [57], which was developed at Ghent University and is commercialized by Teledyne CETAC Technologies, was also used to provide rapid aerosol washout, higher sensitivity and higher spatial resolution.

This study illustrates the capabilities of LA-ICP-MS to perform high-resolution mapping of the distribution of this metal-containing drug on a cellular level, by localizing cisplatin in representative formalin-fixed, paraffin-embedded kidneys from Cynomolgus monkeys with cisplatin-induced cortical proximal tubular lesions. To the best of the authors' knowledge, this is the first time renal cisplatin distribution patterns have been revealed on a (sub-)cellular level in combination with histopathological findings in Cynomolgus monkey kidneys via high-resolution LA-ICP-MS imaging.

\section{Experimental section}

\subsection{Samples and standards}

The kidney tissues originated from a 4-day cisplatin nephrotoxicity study in male and female Cynomolgus monkeys (Macaca fascicularis). The testing facility was located at WuXi AppTec Co., Ltd. (Suzhou, China) and all steps in this research were performed in compliance with the regulations and guidelines concerning animal care and welfare, according to the AAALAC International 
guidelines, as stated in the Guide for the Care and Use of Laboratory Animals (National Research Council, 2011) and the Regulations for the Administration of Affairs Concerning Experimental Animals (People's Republic of China, Ministry of Science \& Technology, 1988). Twenty-four animals, including twelve males and twelve females, were randomly divided into 4 groups and were intravenously administered with a single infusion of vehicle $(0.9 \% \mathrm{NaCl})$ or cisplatin $\left(0.625,1.25\right.$ and $2.50 \mu \mathrm{g} \mathrm{g}^{-1}$ body weight $\left.(\mathrm{bw})\right)$ in the same vehicle. The high dose $\left(2.50 \mu \mathrm{g} \mathrm{g}^{-1} \mathrm{bw}\right)$ was selected to induce minimal-to-marked kidney lesions, whereas the mid dose $\left(1.25 \mu \mathrm{g} \mathrm{g}^{-1}\right.$ bw) could lead to minimal kidney damage. The low dose $\left(0.625 \mu \mathrm{g} \mathrm{g}^{-1} \mathrm{bw}\right)$ was assumed to induce minimal systemic toxicity. Yellowto-orange cisplatin powder (100\% purity) (Fitzgerald Industries International, Acton, MA, USA) was used to prepare the infuse solutions, by dissolving specific amounts of powder in vehicle solution. The animals were housed in a controlled environment under a 12-hour light/dark cycle with free access to water and were fed twice a day. Four days after administration, the animals were anesthetized and euthanized, followed by tissue collection. Kidney tissues intended for LA-ICP-MS analysis were formalin-fixed in $10 \%$ neutral buffered formalin and paraffin-embedded (FFPE). The FFPE kidney sections were sectioned into $5 \mu \mathrm{m}$ thin sections, which were placed on Superfrost glass microscopic slides (Thermo Fisher Scientific, Waltham, MA, USA).

The preparation procedure for the gelatin standard solutions $(10 \% \mathrm{w} / \mathrm{v})$ started with the addition of $100 \mathrm{mg}$ of gelatin powder (VWR International, Leuven, Belgium) into a $1.5 \mathrm{~mL}$ microcentrifuge tube [34]. Different volumes of $1,000 \mu \mathrm{g} \mathrm{mL} \mathrm{m}^{-1} \mathrm{Pt}$ and In stock solutions (Inorganic Ventures, USA) were added to the gelatin powder. Milli-Q water from a purification system, Direct-Q3 (Millipore, Molsheim, France) was added as to obtain a 0 (blank), 10, 20 or $50 \mu \mathrm{g} \mathrm{g}^{-1} \mathrm{Pt}$ standard with $50 \mu \mathrm{g} \mathrm{g}^{-1} \mathrm{In}$. The microcentrifuge tubes were placed in a laboratory water bath at $65^{\circ} \mathrm{C}$ to melt the gelatin and proper mixing was achieved by placing the tubes for 2 minutes onto a vortex system (VWR International, Leuven, Belgium). Four gelatin standard solutions were spotted with a micropipette onto a microscope cover glass and the tiny droplets of 200 - $400 \mu \mathrm{g}$ were weighed using a M3P microbalance (Sartorius, Göttingen, Germany).

\subsection{Instrumentation}

An Analyte G2 193 nm ArF* excimer-based laser ablation (LA) system (Teledyne CETAC Technologies, Omaha, NE, USA) was coupled to a quadrupole-based XSeries-II ICP-MS instrument (Thermo Fisher Scientific, Santa Clara, CA, USA) to map the Pt distribution in Cynomolgus monkey FFPE kidney sections with laterally resolved pixels down to $3 \mu \mathrm{m}$. The LA system was equipped with a HelEx II 2-volume ablation cell. Helium was used as a carrier gas for aerosol transport from the sample surface to the ICP and was mixed with Ar as a make-up gas in an ARIS mixing bulb before entering the plasma. Operational parameters of the ICP-MS and laser were tuned for maximum sensitivity, low oxide formation $(<1 \%)$ based on the ${ }^{238} \mathrm{U}^{16} \mathrm{O}^{+} / 238 \mathrm{U}^{+}$ratio and low laser-induced elemental fractionation based on the ${ }^{238} \mathrm{U}^{+} / 232 \mathrm{Th}^{+}$ratio $(\approx 1)$ using NIST SRM 612 glass certified reference material (National Institute for Standards and Technology, Gaithersburg, MD, USA). In order to evaluate the macroscopic cisplatin distribution in regions of the renal cortex and medulla, an overview scan of a radial segment crossing through these regions was desired; a radial segment was rastered using adjacent scans with a circular laser spot of $15 \mu \mathrm{m}$ diameter, $4.72 \mathrm{~J} \mathrm{~cm}^{-2}$ output energy, $120 \mu \mathrm{m} \mathrm{s}^{-1} \mathrm{scan}$ speed, $50 \mathrm{~Hz}$ repetition rate. The optimal conditions were achieved at a radiofrequency (RF) power of $1350 \mathrm{~W}$ and cooling gas (Ar), auxiliary gas (Ar) and make-up gas (Ar) flow rates of $13,0.70$ and $0.68 \mathrm{~L} \mathrm{~min}^{-1}$, respectively. The carrier gas $(\mathrm{He})$ flow rates were optimized to $0.49-0.55 \mathrm{~L} \mathrm{~min}{ }^{-1} .{ }^{195} \mathrm{Pt}$ and ${ }^{115} \mathrm{In}$ 
were monitored with dwell times of 25 and $7 \mathrm{~ms}$, respectively. Small cortical regions of interest (ROI), selected based on features in the hematoxylin and eosin (H\&E)-stained sequential section were analysed with higher spatial resolution. The laser parameters were adjusted to a circular spot size with a diameter of $3 \mu \mathrm{m}, 3.04 \mathrm{~J} \mathrm{~cm}^{-2}$ output energy, $20 \mu \mathrm{m} \mathrm{s}^{-1}$ scan speed and $60 \mathrm{~Hz}$ repetition rate. The size of the rastered zone was adjusted to match the ROI. The laser ablation system was also coupled to a quadrupole-based Agilent 7900 ICP-MS (Agilent Technologies, Waltham, MA, USA) to enable laterally resolved pixels of $1 \mu \mathrm{m}$ in the ROI images. $\dagger$

\subsection{Calibration}

External calibration, based on spiked gelatin droplet standards, was applied for the quantification of cisplatin in selected radial segment scans. Spotted, spiked droplets were ablated in their entirety prior to mapping, whilst applying identical instrument settings and data acquisition parameters. Signal responses for each mass channel monitored during ablation of a single spiked droplet were integrated after background subtraction. The integrated signal of In, which was incorporated in the gelatin as an internal standard, was used to correct for sensitivity drift throughout the measurement runs. The ${ }^{195} \mathrm{Pt}$ integrated response $R_{P t, i}$ for each droplet $i$ was normalized using the

${ }^{115}$ In integrated response $R_{I n, i}$ of the droplet $i$, its mass $m_{i}$, and the temporally-averaged ${ }^{115}$ In integrated response $\overline{R_{I n}}$ of all $n$ droplets and the average mass of all $n$ droplets $\bar{m}$. The normalized ${ }^{195} \mathrm{Pt}$ response $R_{P t \text { norm, } i}$ of droplet $i$ thus equals:

$$
\begin{gathered}
R_{P t \text { norm }, i}=R_{P t, i} \cdot R_{I n, i}^{-1} \cdot \overline{R_{I n}} \cdot m_{i} \cdot \bar{m}^{-1} \\
\text { with } \overline{R_{I n}}=\frac{1}{n} \sum_{i=1}^{n} R_{I n, i} \text { and } \bar{m}=\frac{1}{n} \sum_{i=1}^{n} m_{i}
\end{gathered}
$$

The normalized ${ }^{195} \mathrm{Pt}$ responses and absolute $\mathrm{Pt}$ masses of each droplet were used to set up the calibration curve. A good linear fit $\left(\mathrm{r}^{2}=\right.$ 0.9998) to the calibration curve, low absolute limits of detection (90 ag for $\left.{ }^{195} \mathrm{Pt}\right) \dagger$ and an absolute sensitivity of 45 cts fg ${ }^{-1}$ were obtained. In order to obtain relative concentrations for the radial segment scans, the total ablated tissue mass per pixel $\left(m_{p}\right)$ can be calculated based on the tissue thickness $(\delta)$ prior to drying, distance covered during one sweep $(x)$, beam waist dimensions $(d)$ and tissue density $(\rho)$.

$$
m_{p}=\delta \cdot x \cdot d \cdot \rho
$$

The relative sensitivity was calculated at $15 \mathrm{cts} / \mathrm{\mu g} \mathrm{g}^{-1}$ and after error propagation through the whole quantification process, a residual standard deviation (RSD) on the relative sensitivity was estimated at $4.2 \%$.

\section{Results and discussion}

\subsection{Quantitative imaging of the cisplatin distribution in renal cortex and medulla}

Radial segments of $13.8 \mathrm{~mm}^{2}(7,079 \times 1,950 \mu \mathrm{m})$ were selected on sequential H\&E-stained and unstained $5 \mu \mathrm{m}$ thick FFPE kidney tissue sections of Cynomolgus monkeys treated with the medium or high dose of cisplatin in order to investigate the cisplatin distribution. For the renal medulla, a distinction was made between the outer stripe of the outer medulla (OSOM) and the inner stripe of the ou ter medulla (ISOM). Specific tubular segments located in the OSOM are the thick segments of both the descending (proximal straight tubules) and ascending limbs. In the ISOM, thin descending and ascending parts of Henle's loop and collecting ducts make up the renal tissue. Overview scans for an animal treated with the high dose of cisplatin are presented below. Figures $2 \mathrm{a}$ and $2 \mathrm{c}$ display two brightfield 
micrographs of the selected radial segments, with an overlay indicating the border between the OSOM and ISOM. Their accompanying $2 \mathrm{D}$ elemental maps in Figures $2 \mathrm{~b}$ and $2 \mathrm{~d}$ show the distribution of cisplatin and its metabolites inside the tissue sections on the basis of the Pt concentration (expressed in $\mu \mathrm{g} \mathrm{g}^{-1}$ ) maps. The highest Pt response is observed in the renal cortex, where proximal tubules and distal tubules are ubiquitous. This is in accordance with the findings of previous studies $[32,35,36,58]$. Despite the fact that study animals and applied doses of cisplatin differ between all works, the highest accumulation of cisplatin was systematically observed in cortical tissue. Vascular elements such as interlobular arteries and veins, marked by the blue arrows in Figures 2a and 2c, can be distinguished and show relatively lower responses in the cortical zones. Black arrows point out renal corpuscles, responsible for the blood filtration; these glomeruli are characterized by low cisplatin levels as well. When comparing both Pt distribution maps, similar distribution patterns are observed for the H\&E-stained and unstained tissue sections, as expected. However, in the unstained Pt distribution map, small tubular structures, such as some cortical renal corpuscles and lumens of tubular segments in the ISOM, can be distinguished more easily. The H\&E-staining procedure may be able to remobilize the cisplatin to some extent, which is preferably avoided. Hence, all of the following experiments were performed on unstained tissue sections. Table 1 contains the average Pt concentrations in the renal cortex and OSOM and in the ISOM for an animal treated with the medium and high dose of cisplatin. In both cases, the highest concentrations were observed in the region covering the renal cortex and OSOM. Raising the dose of cisplatin from 1.25 to $2.50 \mu \mathrm{g} \mathrm{g}^{-1} \mathrm{bw}$ does not appear to increase the local Pt concentration in the ISOM $\left(1.68 \pm 0.11 \mu \mathrm{g} \mathrm{g}^{-1}\right.$ vs. $\left.1.72 \pm 0.09 \mu \mathrm{g} \mathrm{g}^{-1}\right)$, in contrary to the cortex and OSOM, where elevated concentrations were observed. Average concentrations in this region increased from 2.47 to $3.29 \mu \mathrm{g} \mathrm{g}^{-1}$ (33\%), likely as a result of the increased reabsorption and accumulation of cisplatin in the epithelium of proximal and distal tubules. For rats it is also known that the epithelium of proximal straight tubules, present in the OSOM, accumulates high amounts of cisplatin [15].



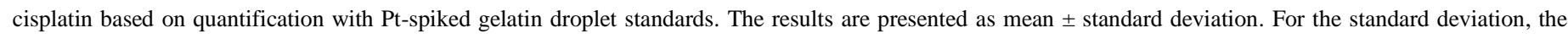

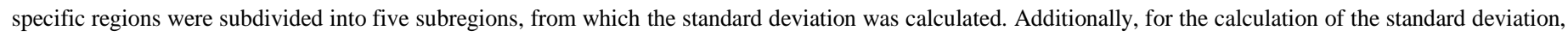

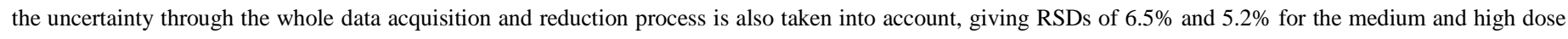
tissue sections, respectively.

\begin{tabular}{|ccc|}
\hline $\begin{array}{c}\text { Dose of } \\
\text { cisplatin }\end{array}$ & $\begin{array}{c}\text { Pt conc. } \\
\text { cortex + OSOM }\end{array}$ & ISOM \\
$\left(\mu \mathrm{g} \mathrm{g}^{-1} \mathrm{bw}\right)$ & $\left(\mu \mathrm{g} \mathrm{g}^{-1}\right)$ & $\left(\mu \mathrm{g} \mathrm{g}^{-1}\right)$ \\
\hline 1.25 & $2.47 \pm 0.16$ & $1.68 \pm 0.11$ \\
2.50 & $3.29 \pm 0.17$ & $1.72 \pm 0.09$
\end{tabular}



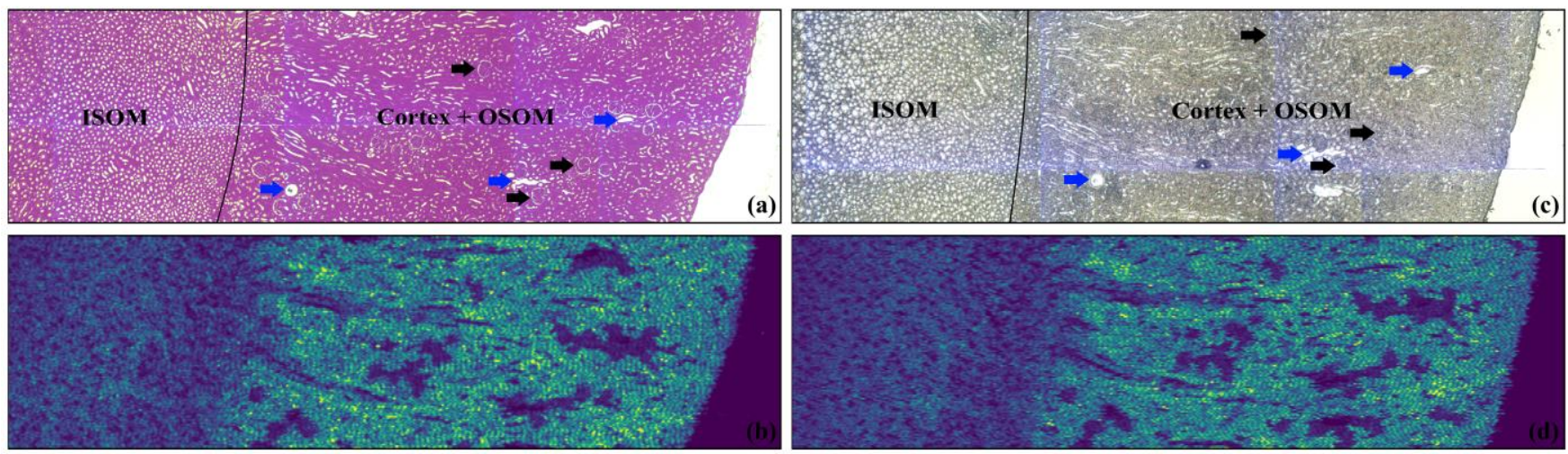

Pt concentration $\left(\mu g g^{-1}\right)$

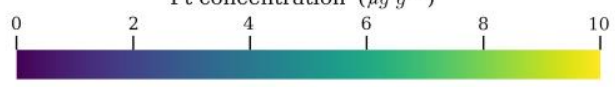

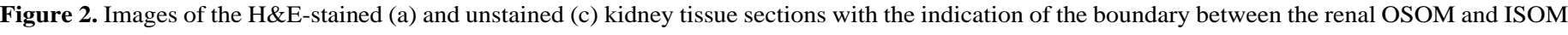

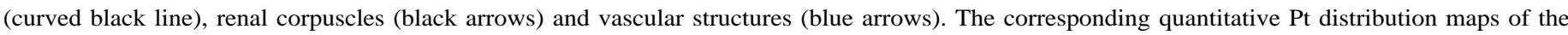
H\&E-stained (b) and unstained (d) kidney tissue sections were obtained via LA-ICP-MS with laterally resolved pixels of $15 \mu \mathrm{m}$.

Combining the regions of the OSOM and ISOM enabled the calculation of the average Pt concentrations in medullary tissue, corresponding to $1.99 \pm 0.13$ and $2.10 \pm 0.11 \mu \mathrm{g} \mathrm{g}^{-1}$ for the medium and high dose, respectively. The average medullary Pt concentrations are similar for both doses. Egger et al. [32] reported average Pt concentrations of 0.8 and $9 \mu \mathrm{g} \mathrm{g}^{-1}$ for the renal medulla and cortex in mice, sacrificed 24 hours after administration of a $15 \mu \mathrm{g} \mathrm{g}^{-1}$ bw single dose of cisplatin. Since in our work, the time of sacrifice is 96 hours after administration and the doses of cisplatin are a factor 6-8 lower, average Pt concentrations in cortical tissue are lower (2.47 3.29 vs. $9 \mu \mathrm{g} \mathrm{g}^{-1}$ ). In conclusion, these quantitative results confirm the higher degree of cisplatin reabsorption and accumulation in epithelial cells of proximal and distal tubules, in comparison with the tubular segments in the ISOM.

\subsection{High-resolution imaging and combination with histopathological examination of small cortical regions of interest}

Renal tubular lesions were histologically mainly identified in the cortex and OSOM of animals administered with medium and high doses of cisplatin - which were very likely induced by the relatively high amount of cisplatin in this zone. Histologically, the proximal tubules showed tubular dilatation with swelling and vacuolation of tubular epithelial cells and minimal to mild multifocal necrosis of the proximal tubular epithelium with sloughing of these necrotic epithelial cells into the tubular lumen. Additional cisplatin-induced lesions were hyaline casts within the lumen of distal tubules and minimal multifocal acute/subchronic cortical inflammation. The glomeruli were histologically unaffected at these cisplatin concentrations.

Specific regions of interest encompassing these microscopic lesions were selected to examine whether or not they could be directly linked to regions with high cisplatin concentrations. A composite image of the sequential H\&E-stained sections with the ROI zones identified was overlaid onto the live image unstained section, based on characteristic marker features that the images share. Since Pt responses for the high-resolution LA-ICP-MS images are very low, Poisson-type noise affected images were denoised applying a highquality denoising algorithm in the PureDenoise ImageJ plugin [59]. As can be seen in the high-resolution LA-ICP-MS image in Figure 
3, the Pt distribution in a region with focal subchronic cortical interstitial inflammation was investigated. The extravascular intertubular areas within the renal tissue constitute the interstitium [60]. The subchronic inflammatory cell infiltrate was mainly composed of lymphocytes, macrophages and neutrophils [61]. The inflammation extends from the top left corner towards the ROI center. This inflammatory region was isolated from the images and after varying the color threshold and applying a mild Gaussian filter, two 8 -bit type images were combined as a red, green and blue (RGB) color stack in order to visualize the correlation between the presence of inflammation and cisplatin. Downsampling of this region was necessary to reduce noise levels. Numerical values were compared pixelwise and Spearman's rank-order correlation coefficient $\left(r_{s}\right)$ was calculated in SPSS statistics software. A significant strongly negative correlation was determined between the presence of inflammation and cisplatin $\left(\mathrm{r}_{\mathrm{s}}=-0.958, \mathrm{~N}=4015, \mathrm{p}<0.0001\right)$ and therefore, the $\mathrm{Pt}$ response in this inflammation region is very low. Different tubular structures can be recognized in the Pt distribution map and as expected, cisplatin is mainly present in the epithelial cells of proximal and distal tubules. Previous studies [35,36] on this topic also indicate the accumulation of cisplatin in tubular epithelial cells. The lumens of these tubular segments are low in cisplatin. The luminal diameter of distal tubules seems to be larger because of the lack of long microvilli, which are only present in proximal tubules.

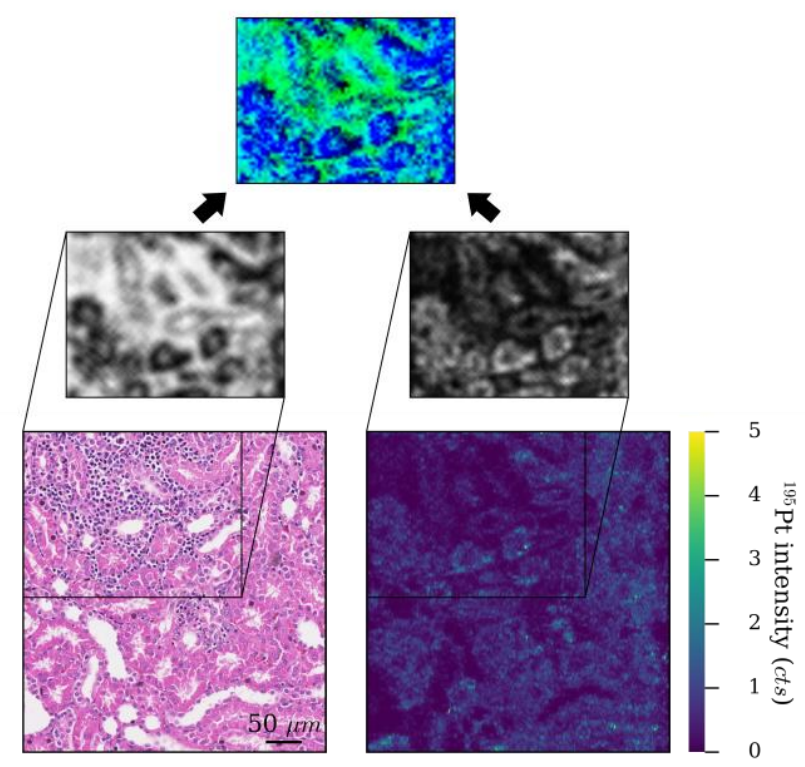

Figure 3. High-resolution brightfield micrograph of a selected region with focal subchronic cortical interstitial inflammation on an H\&E-stained kidney tissue section of an animal treated with the medium dose of cisplatin (bottom left) and the corresponding ${ }^{195} \mathrm{Pt}$ distribution map (bottom right), obtained by analyzing the adjacent unstained kidney tissue section with a circular spot size diameter of $3 \mu \mathrm{m}$. The 8 -bit type images of the isolated inflammation region (middle) form the basis of the RGB color stack image which visualizes the negative correlation between the presence of inflammation and cisplatin (top).

In Figure 4, the focus is on the correlation between the accumulation of cisplatin and the presence of focal necrosis of proximal tubular epithelial cells. Since epithelial cells of proximal and distal tubules reabsorb significant amounts of cisplatin, accumulation can lead to certain cytotoxic levels of cisplatin, which can result into cell death. Necrosis involves drastic irreversible changes in the cytoplasm and nucleus [62]. This phenomenon is characterized by the presence of hypereosinophilic round cells with pycnotic nuclei, which are often 
sloughed into the tubular lumen. These sloughed epithelial cells within the tubular lumen are visible in the high-resolution images of Figures $4 \mathrm{a}-4 \mathrm{c}$, and correlate strongly to the highest Pt response and therefore, with high accumulation of cisplatin. Especially in Figure 4b, a large necrotizing tubulus with many sloughed cells in its lumen clearly correlates to the region with the highest Pt response. Additionally, black arrows in Figure $4 \mathrm{a}$ indicate intratubular hyaline casts, the major constituent of which is the Tamm-Horsfall glycoprotein, which is only secreted by the epithelium of the thick ascending limb of Henle's loop and a short segment of the DCTs [63]. In general, these hyaline casts seem to contain low cisplatin concentrations. Furthermore, as seen in Figure 3, the characteristic tubular structures can be observed in the Pt distribution maps, thus demonstrating the ability of LA-ICP-MS to reveal cellular cisplatin distribution patterns.

The coupling of the Analyte G2 laser ablation system to the Agilent 7900 ICP-MS allowed even smaller spot sizes down to $1 \mu \mathrm{m}$, as a direct result of its inherent higher sensitivity. A small ROI $(266$ x $300 \mu \mathrm{m})$ was selected on the H\&E-stained tissue section with focal tubular necrosis of proximal tubular epithelium and this corresponding area was ablated on the adjacent unstained tissue section. Figure $4 \mathrm{c}$ presents the high-resolution image of this region and the corresponding $\mathrm{Pt}$ distribution map. Applying the $\mu \mathrm{m}$ lateral resolution increases the measurement time considerably but it provides spatially more detailed information on the cisplatin distribution. The boundaries between the different tubular structures can be observed more easily and based on the difference in Pt response within their lumens, it is possible to distinguish between proximal and distal tubules. The glomerulus at the right side of the image corresponds to the dark blue zone, indicating very low cisplatin accumulation, which is in agreement with the findings of Moreno-Gordaliza et al. [36], who indicated cisplatin was absent in glomeruli. In contrast to our results based on a single dose administration, Köppen et al. [35] reported the presence of significant amounts of cisplatin in the glomeruli of mice kidneys after cisplatin administration of eight doses of $4 \mu \mathrm{g} \mathrm{g}^{-1}$ bw during four weeks (twice a week). In the cortical regions with tubular necrosis, the degree of Pt accumulation is very high in comparison with that of the surrounding cortical tissue. The highest cisplatin accumulation in this example can be linked to the presence of sloughed necrotic epithelial cells, which appear as round cells with pycnotic nuclei in the lumen of proximal tubules. 
(a)

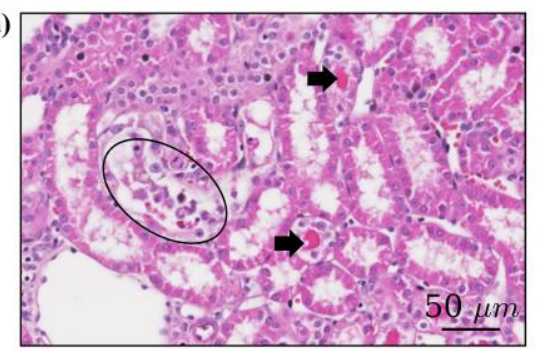

(b)

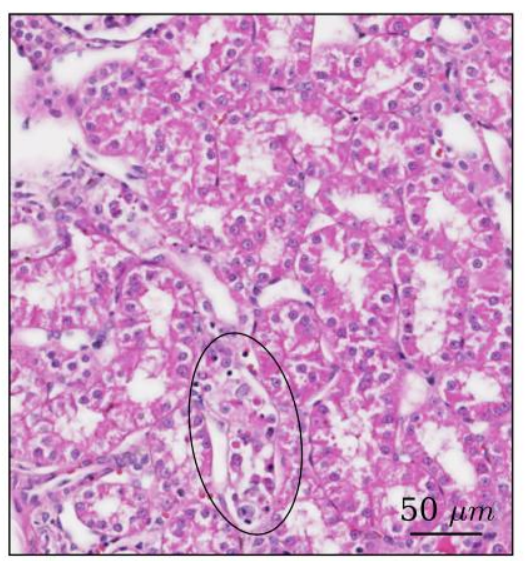

(c)

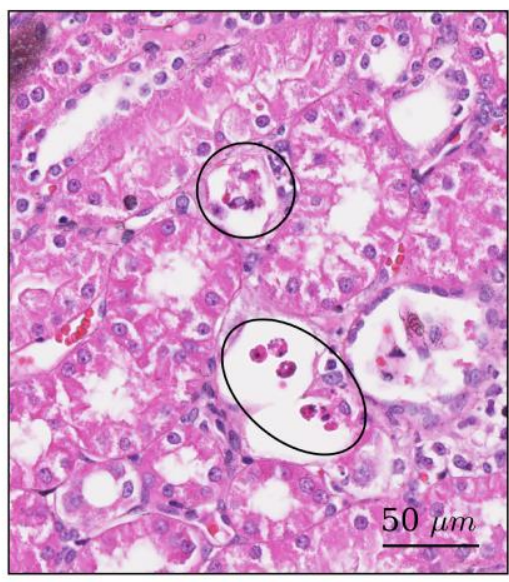

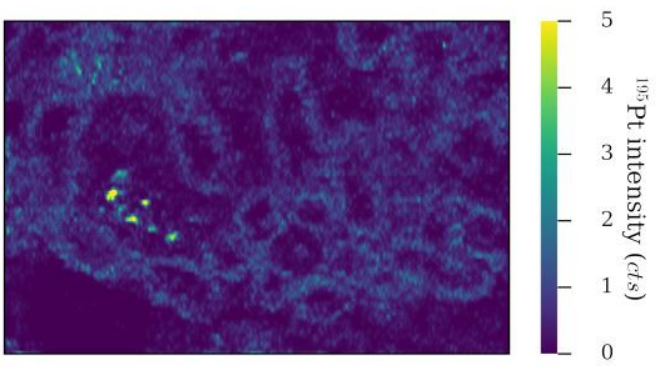
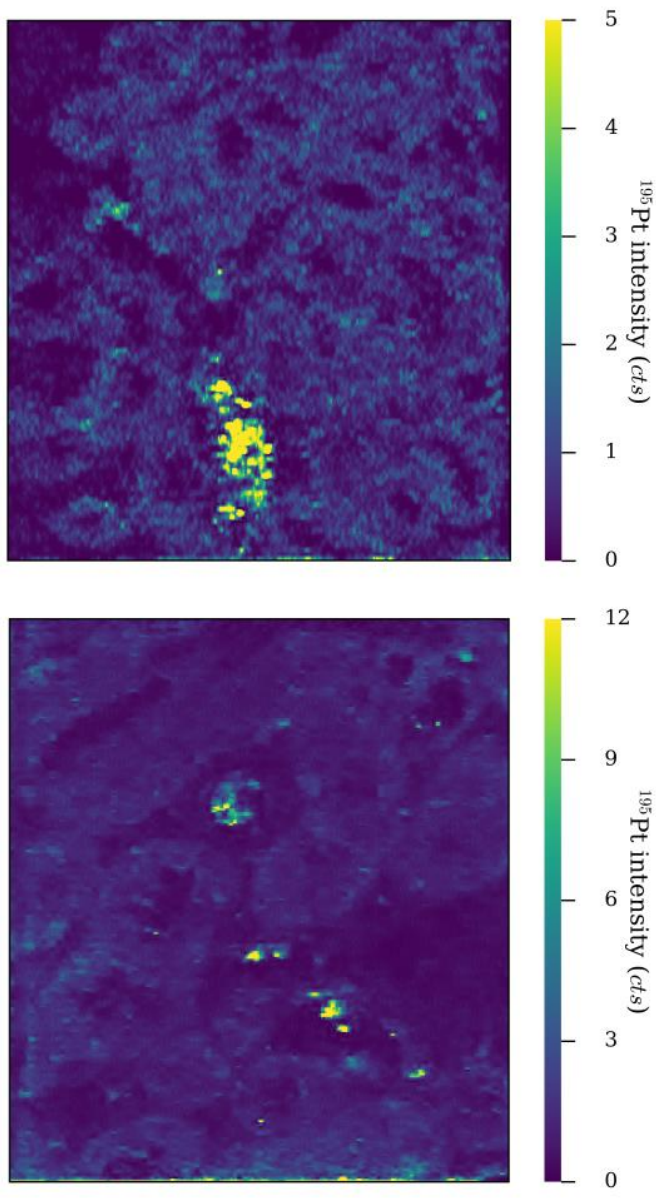

Figure 4. High-resolution brightfield microscopy images of selected regions of interest with focal necrosis of proximal tubular epithelium on the H\&Estained kidney tissue sections of Cynomolgus monkeys administered with the medium (a) and high (b and c) dose of cisplatin with the corresponding ${ }^{195} \mathrm{Pt}$ distribution maps obtained by analyzing the adjacent unstained kidney tissue sections with a circular spot size diameter of 3 (a and b) and $1 \mu \mathrm{m}$ (c). Intratubular hyaline casts are indicated by the black arrows.

\section{Conclusions}

The mapping of the Pt signal intensities in sections of Cynomolgus monkey kidney tissue via LA-ICP-MS allowed the examination of the distribution of the chemotherapeutic drug cisplatin on a cellular scale. Quantitative results were obtained for selected radial segment scans based on external calibration with spiked gelatin droplets, giving low absolute limits of detection ( 90 ag for Pt), good linear fit to the calibration curve $\left(\mathrm{r}^{2}=0.9998\right)$ and high absolute sensitivity $\left(45 \mathrm{cts} \mathrm{fg}^{-1}\right)$. The combination of the high-resolution Pt distribution maps 
with minimal to mild microscopic kidney injury identified on adjacent H\&E-stained tissue sections demonstrated the correlation between microscopic lesions and the local accumulation of cisplatin. The highest accumulation of cisplatin was detected in the renal cortical tubules, especially in the tubular epithelial cells. The presence of necrotic proximal tubules with sloughed epithelial cells in their lumen correlated strongly to the highest Pt signal responses, which suggests that high accumulation of cisplatin in those areas, directly caused multifocal renal damage. The active protective response in regions with subchronic cortical interstitial inflammation showed very low cisplatin concentrations in comparison with the surrounding tissue. Very low levels of cisplatin were also demonstrated in hyaline casts, but their occurrence could be seen as an indirect pathway of renal damage. This research demonstrated the potential of high-resolution bioimaging via LA-ICP-MS by visualizing the cisplatin distribution in Cynomolgus monkey renal tissues on a (sub-)cellular level.

\section{Notes}

$\uparrow$ Supporting information available

The authors declare the following competing financial interest(s): This work was partly funded by Teledyne CETAC Technologies and Janssen Pharmaceutica NV.

\section{Acknowledgements}

The authors acknowledge Janssen Pharmaceutica NV, Teledyne CETAC Technologies and the Flemish Research Foundation (FWO) for financial and/or logistic support. Stijn J. M. Van Malderen is a PhD fellow of the FWO. Furthermore, the authors acknowledge study pathologist Charlie Johnson for his contribution to this study.

\section{References}

[1] C.A. Rabik, M.E. Dolan, Molecular mechanisms of resistance and toxicity associated with platinating agents, Cancer Treat. Rev. 33 (2007) 9-23.

[2] D. Wang, S.J. Lippard, Cellular processing of platinum anticancer drugs, Nat. Rev. Drug Discov. 4 (2005) 307-320.

[3] G.-S. Oh, H.J. Kim, A. Shen, S. Bin Lee, D. Khadka, A. Pandit, H.S. So, Cisplatin-induced kidney dysfunction and perspectives on improving treatment strategies, Electrolyte Blood Press. 12 (2014) 55-65.

[4] N. Pabla, Z. Dong, Cisplatin nephrotoxicity: Mechanisms and renoprotective strategies, Kidney Int. 73 (2008) 994-1007.

[5] M. Schetz, J. Dasta, S. Goldstein, T. Golper, Drug-induced acute kidney injury, Curr. Opin. Crit. Care. 11 (2005) 555-565.

[6] A. Benjamin, A.N. da Costa, A. Delaunois, M.-L. Rosseels, P. Valentin, Renal Safety Pharmacology in Drug Discovery and Development, in: M.K. Pugsley, M.J. Curtis (Eds.), Princ. Saf. Pharmacol., 1st ed., Springer, Berlin Heidelberg, 2015: pp. 323-352.

[7] M.J. Waring, J. Arrowsmith, A.R. Leach, P.D. Leeson, S. Mandrell, R.M. Owen, G. Pairaudeau, W.D. Pennie, S.D. Pickett, J. Wang, O. Wallace, A. Weir, An analysis of the attrition of drug candidates from four major pharmaceutical companies, Nat. Rev. Drug Discov. 14 (2015) $475-486$.

[8] V.A. Luyckx, S. Naicker, Acute kindey injury associated with the use of traditional medicines, Nat. Rev. Nephrol. 4 (2008) 664-671.

[9] V. Cepeda, M.A. Fuertes, J. Castilla, C. Alonso, C. Quevedo, J.M. Pérez, Biochemical Mechanisms of Cisplatin Cytotoxicity, Anticancer. Agents Med. Chem. 7 (2007) 3-18.

[10] D.C. Eaton, J.P. Pooler, Renal Functions, Basic Processes, and Anatomy, in: D.C. Eaton, J.P. Pooler (Eds.), Vander's Ren. Physiol., 8th ed., McGrawHill, New York, 2013: pp. 1-19. 
[11] A.L. Mescher, The Urinary System, in: A.L. Mescher (Ed.), Junqueira’s Basic Histol. Text Atlas, 13th ed., McGraw-Hill, New York, 2013 : pp. 385-403.

[12] W. Kriz, L. Bankir, A standard nomenclature for structures of the kidney, Kidney Int. 33 (1988) 1-7.

[13] D. Esteban-Fernández, E. Moreno-Gordaliza, B. Cañas, M.A. Palacios, M.M. Gómez-Gómez, Analytical methodologies for metallomics studies of antitumor Pt-containing drugs, Metallomics. 2 (2010) 19-38.

[14] A. Yonezawa, K.-I. Inui, Organic cation transporter OCT/SLC22A and H+/organic cation antiporter MATE/SLC47A are key molecules for nephrotoxicity of platinum agents, Biochem. Pharmacol. 81 (2011) 563-568.

[15] X. Yao, K. Panichpisal, N. Kurtzman, K. Nugent, Cisplatin Nephrotoxicity: A Review, Am. J. Med. Sci. 334 (2007) 115-124.

[16] S. Wang, R. Brown, D.J. Gray, Application of Laser Ablation-ICPMS to the Spatially Resolved Micro-analysis of Biological Tissue, Appl. Spectrosc. 48 (1994) 1321-1325.

[17] D.J. Hare, J.L. George, R. Grimm, S. Wilkins, P.A. Adlard, R.A. Cherny, A.I. Bush, D.I. Finkelstein, P. Doble, Three-dimensional elemental bio-imaging of $\mathrm{Fe}, \mathrm{Zn}, \mathrm{Cu}, \mathrm{Mn}$ and $\mathrm{P}$ in a 6-hydroxydopamine lesioned mouse brain, Metallomics. 2 (2010) 745-753.

[18] A. Matusch, C. Depboylu, C. Palm, B. Wu, G.U. Höglinger, M.K.-H. Schäfer, J.S. Becker, Cerebral Bioimaging of Cu, Fe, Zn, and Mn in the MPTP Mouse Model of Parkinson's Disease Using Laser Ablation Inductively Coupled Plasma Mass Spectrometry (LA-ICP-MS), J. Am. Soc. Mass Spectrom. 21 (2010) 161-171

[19] J.S. Becker, U. Breuer, H.-F. Hsieh, T. Osterholt, U. Kumtabtim, B. Wu, A. Matusch, J.A. Caruso, Z. Qin, Bioimaging of metals and biomolecules in mouse heart by laser ablation inductively coupled plasma mass spectrometry and secondary ion mass spectrometry, Anal. Chem. 82 (2010) $9528-9533$.

[20] J.S. Becker, U. Kumtabtim, B. Wu, P. Steinacker, M. Otto, A. Matusch, Mass spectrometry imaging (MSI) of metals in mouse spinal cord by laser ablation ICP-MS, Metallomics. 4 (2012) 284-288.

[21] J.S. Becker, M. V. Zoriy, C. Pickhardt, N. Palomero-Gallagher, K. Zilles, Imaging of copper, zinc, and other elements in thin section of human brain samples (hippocampus) by laser ablation inductively coupled plasma mass spectrometry, Anal. Chem. 77 (2005) 3208-3216.

[22] D. Hare, S. Tolmachev, A. James, D. Bishop, C. Austin, F. Fryer, P. Doble, Elemental bio-imaging of thorium, uranium, and plutonium in tissues from occupationally exposed former nuclear workers, Anal. Chem. 82 (2010) 3176-3182.

[23] D. Hare, F. Burger, C. Austin, F. Fryer, R. Grimm, B. Reedy, R. a Scolyer, J.F. Thompson, P. Doble, Elemental bio-imaging of melanoma in lymph node biopsies., Analyst. 134 (2009) 450-453.

[24] M. Vašinová Galiová, R. Čopjaková, R. Škoda, K. Štěpánková, M. Vaňková, J. Kuta, L. Prokeš, J. Kynický, V. Kanický, 2D elemental mapping of sections of human kidney stones using laser ablation inductively-coupled plasma-mass spectrometry: Possibilities and limitations, Spectrochim. Acta Part B At. Spectrosc. 100 (2014) 105-115.

[25] L. Waentig, S. Techritz, N. Jakubowski, P.H. Roos, A multi-parametric microarray for protein profiling: simultaneous analysis of 8 different cytochromes via differentially element tagged antibodies and laser ablation ICP-MS, Analyst. 138 (2013) 6309-6315.

[26] A.J. Managh, R.W. Hutchinson, P. Riquelme, C. Broichhausen, A.K. Wege, U. Ritter, N. Ahrens, G.E. Koehl, L. Walter, C. Florian, H.J. Schlitt, H.J. Reid, E.K. Geissler, B.L. Sharp, J.A. Hutchinson, Laser Ablation-Inductively Coupled Plasma Mass Spectrometry: An Emerging Technology for Detecting Rare Cells in Tissue Sections, J. Immunol. 193 (2014) 2600-2608.

R.W. Hutchinson, A.G. Cox, C.W. McLeod, P.S. Marshall, A. Harper, E.L. Dawson, D.R. Howlett, Imaging and spatial distribution of $\beta$-amyloid peptide and metal ions in Alzheimer's plaques by laser ablation-inductively coupled plasma-mass spectrometry, Anal. Biochem. 346 (2005) $225-233$. L. Waentig, N. Jakubowski, S. Hardt, C. Scheler, P.H. Roos, M.W. Linscheid, Comparison of different chelates for lanthanide labeling of antibodies and application in a Western blot immunoassay combined with detection by laser ablation (LA-)ICP-MS, J. Anal. At. Spectrom. 27 (2012) 1311-1320. 
labeled antibodies and laser ablation inductively coupled plasma mass spectrometry (LA-ICP-MS), Anal. Chem. 85 (2013) $5047-5054$.

[30] C. Giesen, T. Mairinger, L. Khoury, L. Waentig, N. Jakubowski, U. Panne, Multiplexed immunohistochemical detection of tumor markers in breast cancer tissue using laser ablation inductively coupled plasma mass spectrometry, Anal. Chem. 83 (2011) 8177-8183.

[31] C. Giesen, H.A.O. Wang, D. Schapiro, N. Zivanovic, A. Jacobs, B. Hattendorf, P.J. Schüffler, D. Grolimund, J.M. Buhmann, S. Brandt, Z. Varga, P.J. Wild, D. Günther, B. Bodenmiller, Highly multiplexed imaging of tumor tissues with subcellular resolution by mass cytometry, Nat. Methods. 11 (2014) $417-422$.

[32] A.E. Egger, S. Theiner, C. Kornauth, P. Heffeter, W. Berger, B.K. Keppler, C.G. Hartinger, Quantitative bioimaging by LA-ICP-MS: a methodological study on the distribution of Pt and Ru in viscera originating from cisplatin- and KP1339-treated mice, Metallomics. 6 (2014) 1616-1625.

[33] A.E. Egger, C. Kornauth, W. Haslik, S. Hann, S. Theiner, G.G. Bayer, C.G. Hartinger, B.K. Keppler, U. Pluschnig, R.M. Mader, Extravasation of Ptbased Chemotherapeutics - Bioimaging of their Distribution in Resectates by Laser Ablation-Inductively Coupled Plasma-Mass Spectrometry (LA-ICPMS), Metallomics. 7 (2015) 508-515.

[34] D. Gholap, J. Verhulst, W. Ceelen, F. Vanhaecke, Use of pneumatic nebulization and laser ablation-inductively coupled plasma-mass spectrometry to study the distribution and bioavailability of an intraperitoneally administered Pt-containing chemotherapeutic drug, Anal. Bioanal. Chem. 402 (2012) $2121-2129$

[35] C. Köppen, O. Reifschneider, I. Castanheira, M. Sperling, U. Karst, G. Ciarimboli, Quantitative imaging of platinum based on laser ablation-inductively coupled plasma-mass spectrometry to investigate toxic side effects of Cisplatin, Metallomics. 7 (2015) 1595-1603.

[36] E. Moreno-Gordaliza, C. Giesen, A. Lázaro, D. Esteban-Fernández, B. Humanes, B. Cañas, U. Panne, A. Tejedor, N. Jakubowski, M.M. Gómez-Gómez, Elemental bioimaging in kidney by LA-ICP-MS as a tool to study nephrotoxicity and renal protective strategies in cisplatin therapies, Anal. Chem. 83 (2011) 7933-7940.

[37] J. Bianga, A. Bouslimani, N. Bec, F. Quenet, S. Mounicou, J. Szpunar, B. Bouyssiere, R. Lobinski, C. Larroque, Complementarity of MALDI and LA ICP mass spectrometry for platinum anticancer imaging in human tumor, Metallomics. 6 (2014) 1382-1386.

[38] M. Bonta, H. Lohninger, V. Laszlo, B. Hegedus, A. Limbeck, Quantitative LA-ICP-MS imaging of platinum in chemotherapy treated human malignant pleural mesothelioma samples using printed patterns as standard, J. Anal. At. Spectrom. 29 (2014) 2159-2167.

[39] D. Pozebon, V.L. Dressler, A. Matusch, J.S. Becker, Monitoring of platinum in a single hair by laser ablation inductively coupled plasma mass spectrometry (LA-ICP-MS) after cisplatin treatment for cancer, Int. J. Mass Spectrom. 272 (2008) 57-62.

[40] C. Herdering, C.A. Wehe, O. Reifschneider, I. Raj, G. Ciarimboli, K. Diebold, C. Becker, M. Sperling, U. Karst, Laser ablation based bioimaging with simultaneous elemental and molecular mass spectrometry: towards spatially resolved speciation analysis, Rapid Commun. Mass Spectrom. 27 (2013) $2588-2594$.

[41] M. Zoriy, A. Matusch, T. Spruss, J.S. Becker, Laser ablation inductively coupled plasma mass spectrometry for imaging of copper, zinc, and platinum in thin sections of a kidney from a mouse treated with cis-platin, Int. J. Mass Spectrom. 260 (2007) 102-106.

[42] O. Reifschneider, C.A. Wehe, I. Raj, J. Ehmcke, G. Ciarimboli, M. Sperling, U. Karst, Quantitative bioimaging of platinum in polymer embedded mouse organs using laser ablation ICP-MS, Metallomics. 5 (2013) 1440-1447.

[43] N. Miliszkiewicz, S. Walas, A. Tobiasz, Current approaches to calibration of LA-ICP-MS analysis, J. Anal. At. Spectrom. 30 (2015) $327-338$.

[44] D. Pozebon, G.L. Scheffler, V.L. Dressler, M.A.G. Nunes, Review of the applications of laser ablation inductively coupled plasma mass spectrometry (LA-ICP-MS) to the analysis of biological samples, J. Anal. At. Spectrom. 29 (2014) 2204-2228.

[45] D. Günther, B. Hattendorf, Solid sample analysis using laser ablation inductively coupled plasma mass spectrometry, Trends Anal. Chem. 24 (2005) 255265. 
[46] A. Limbeck, P. Galler, M. Bonta, G. Bauer, W. Nischkauer, F. Vanhaecke, Recent advances in quantitative LA-ICP-MS analysis: challenges and solutions in the life sciences and environmental chemistry, Anal. Bioanal. Chem. 407 (2015) 6593-6617.

[47] J.A.T. Pugh, A.G. Cox, C.W. McLeod, J. Bunch, B. Whitby, B. Gordon, T. Kalber, E. White, A novel calibration strategy for analysis and imaging of biological thin sections by laser ablation inductively coupled plasma mass spectrometry, J. Anal. At. Spectrom. 26 (2011) 1667-1673.

[48] C. Austin, D. Hare, T. Rawling, A.M. McDonagh, P. Doble, Quantification method for elemental bio-imaging by LA-ICP-MS using metal spiked PMMA films, J. Anal. At. Spectrom. 25 (2010) 722-725.

[49] D.J. Bellis, R. Santamaria-Fernandez, Ink jet patterns as model samples for the development of LA-ICP-SFMS methodology for mapping of elemental distribution with reference to biological samples, J. Anal. At. Spectrom. 25 (2010) 957-963.

[50] S. Hoesl, B. Neumann, S. Techritz, M. Linscheid, F. Theuring, C. Scheler, N. Jakubowski, L. Mueller, Development of a calibration and standardization procedure for LA-ICP-MS using a conventional ink-jet printer for quantification of proteins in electro- and Western-blot assays, J. Anal. At. Spectrom. 29 (2014) 1282-1291.

[51] S. Hoesl, B. Neumann, S. Techritz, G. Sauter, R. Simon, H. Schlüter, M.W. Linscheid, F. Theuring, N. Jakubowski, L. Mueller, Internal standardization of LA-ICP-MS immuno imaging via printing of universal metal spiked inks onto tissue sections, J. Anal. At. Spectrom. 31 (2016) 801-808.

[52] I. Moraleja, D. Esteban-Fernández, A. Lázaro, B. Humanes, B. Neumann, A. Tejedor, M.L. Mena, N. Jakubowski, M.M. Gómez-Gómez, Printing metalspiked inks for LA-ICP-MS bioimaging internal standardization: comparison of the different nephrotoxic behavior of cisplatin, carboplatin, and oxaliplatin, Anal. Bioanal. Chem. 408 (2016) 2309-2318.

[53] W. Nischkauer, F. Vanhaecke, S. Bernacchi, C. Herwig, A. Limbeck, Radial line-scans as representative sampling strategy in dried-droplet laser ablation of liquid samples deposited on pre-cut filter paper disks, Spectrochim. Acta - Part B At. Spectrosc. 101 (2014) 123-129.

[54] A. Izmer, D. Gholap, K. De Houwer, F. Cuyckens, F. Vanhaecke, A pilot study on the use of laser ablation-ICP-mass spectrometry for assessing/mapping the distribution of a drug and its metabolites across the body compartments of rats, J. Anal. At. Spectrom. 27 (2012) 413-418. M. Birka, K.S. Wentker, E. Lusmöller, B. Arheilger, C.A. Wehe, M. Sperling, R. Stadler, U. Karst, Diagnosis of Nephrogenic Systemic Fibrosis by means of Elemental Bioimaging and Speciation Analysis, Anal. Chem. 87 (2015) 3321-3328.

[56] A.-C. Niehoff, O.B. Bauer, S. Kröger, S. Fingerhut, J. Schulz, S. Meyer, M. Sperling, A. Jeibmann, T. Schwerdtle, U. Karst, Quantitative Bioimaging to Investigate the Uptake of Mercury Species in Drosophila melanogaster, Anal. Chem. 87 (2015) 10392-10396.

[57] Teledyne CETAC Technologies, Aerosol rapid introduction system (ARIS), (2016). http://www.teledynecetac.com/product/laser-ablation/aris (accessed June 7, 2016).

[58] A.A. Legin, S. Theiner, A. Schintlmeister, S. Reipert, M.A. Jakupec, H.P. Varbanov, C.R. Kowol, M. Galanski, W. Berger, M. Wagner, B.K. Keppler, Multi-scale imaging of anticancer platinum(IV) compounds in murine tumor and kidney, 7 (2016) 3052-3061.

[59] F. Luisier, High-quality denoising of multidimensional fluorescence microscopy images, (2014). http://bigwww.epfl.ch/algorithms/denoise/\#ref (accessed September 12, 2016).

[60] K.V. Lemley, W. Kriz, Anatomy of the renal interstitium, Kidney Int. 39 (1991) 370-381.

[61] L. Ferrero-Miliani, O.H. Nielsen, P.S. Andersen, S.E. Girardin, Chronic inflammation: importance of NOD2 and NALP3 in interleukin-1 $\beta$ generation, Clin. Exp. Immunol. 147 (2007) 227-235. 